\title{
Examining the role of IL17RD in development and disease
}

Shivangi Pande

Xuehui Yang

Robert Friesel

\section{Video Byte}

Keywords: Sef, Interleukin-17, Interleukin-17 receptor D (IL17RD), Fibroblast Growth Factor (FGF), Fibroblast Growth Factor Receptor (FGFR), cellular signaling, Cell Communication and Signaling

Posted Date: February 25th, 2021

DOI: https://doi.org/10.21203/rs.3.rs-276052/v1

License: (a) (1) This work is licensed under a Creative Commons Attribution 4.0 International License.

Read Full License 


\section{Abstract}

Interleukin-17 receptor D (IL-17RD), also known as SEF, acts as a key regulator of several signaling pathways. This single pass transmembrane protein was initially discovered as an inhibitor of fibroblast growth factor (FGF) signaling during zebrafish and frog development. but homologs exist in many vertebrate species, including mice and humans, where many isoforms are expressed. IL-17RD is ubiquitously expressed in many organs throughout the body, where it regulates FGF and tyrosine kinase signaling cascades, and proinflammatory signaling pathways, including IL-17A, toll-like receptors (TLRs), IL-1a, TNFa, and the WNT pathway. Genetic alterations in IL-17RD and dysregulation of its expression have been associated with a wide array of conditions. including breast, prostate, thyroid, ovarian, and intestinal cancer and neuroendocrine diseases such as Kallmann syndrome, congenital hypogonadotropic hypogonadism, and delayed puberty. And altered interactions between IL-17RD and its ligands can be a driving factor behind inflammatory diseases such as rheumatoid arthritis and psoriasis. Although significant portions of the IL-17RD signaling pathways have been characterized, several aspects remain to be investigated. Better understanding this pathway will aid in identifying therapeutic targets for regulating dysfunctional IL-17RD signaling. 